\title{
Custeio-Alvo: Um Caso Prático em uma Indústria de Confecções do Polo Têxtil do Agreste Pernambucano
}

\author{
Monike Silva Melo \\ Pós-Graduação em Controladoria pela Universidade Federal Rural de Pernambuco - \\ UFRPE \\ Rua Dom Manoel de Medeiros, s/n. Dois Irmãos. Recife/PE. CEP: 52171-900 \\ E-mail:monike_melo@hotmail.com \\ Antônio André Cunha Callado \\ Pós-Doutorado em Controladoria pela University of Portsmouth \\ Coordenador do Programa de Pós-Graduação em Controladoria na Universidade \\ Federal Rural de Pernambuco - UFRPE \\ Rua Dom Manoel de Medeiros, s/n. Dois Irmãos. Recife/PE. CEP: 52171-900 \\ E-mail: andrecallado1968@gmail.com
}

\section{RESUMO}

Este estudo tem por objetivo analisar a aplicação da metodologia do Custeio-alvo em uma indústria de confecções de moda íntima. Os procedimentos metodológicos consistiram de uma pesquisa descritiva, documental, qualitativa realizada por meio de um estudo em uma empresa localizada no polo têxtil do agreste pernambucano. Para coleta de dados, foram realizadas entrevistas estruturadas e observações diretas considerando uma abordagem de triangulação. Foi observado que a empresa utiliza o método de custeio pleno, mesmo que de forma empírica, para determinar seus gastos. Com a aplicação do custeio-alvo, foi alcançada a redução do custo estimado do produto inicialmente, mas não foi atingido em sua totalidade o custo-alvo. Ainda assim, a empresa optou por dar continuidade ao projeto e iniciar sua produção. Do resultado da pesquisa, pode-se concluir que o método de custeio-alvo é uma ferramenta de gestão estratégica de custos que foi capaz de suprir as necessidades informacionais e de gerenciamento de custos de uma empresa do ramo de confecções.

Palavras-chave: Custos. Análise de custos. Custeio-alvo.

Target Cost: A Practical Case in a Clothing Industry of the Textile Complex in the inland part of Pernambuco

\section{ABSTRACT}

The purpose of this study is to analyze the application of the Target Costing methodology in an intimate apparel industry. The methodological procedures consisted of a descriptive, documentary and qualitative research carried out by means of a study in a company located in the textile pole of the inland part of Pernambuco. For data 
collection, structured interviews and direct observations were performed considering a triangulation approach. It was observed that, although empirically, the company uses the full costing method to determine its expenses. With the application of the target cost, the estimated cost of the product was initially reduced, but the target cost was not fully reached. Even so, the company opted to continue the project and to start the production. From the research results, it can be concluded that the target costing method is a strategic cost management tool that was able to meet the information and cost management needs of a garment company.

Keywords: Costs. Cost analysis. Target costing.

\section{INTRODUÇÃO}

O conceito de Custeio-Alvo surgiu nos anos 1960, no Japão, expandindo os preceitos de Engenharia de Valor. Seu uso é recomendado em ambientes nos quais o preço é determinado pelo mercado e de forte competitividade. $\mathrm{Na}$ literatura, sua aplicação é frequentemente associada a indústrias (Camacho \& Rocha, 2007; Rocha \& Hansen, 2004).

A proliferação dos estudos e o uso dessa ferramenta emergem das constantes mudanças ocorridas no cenário dos negócios em virtude da concorrência global e da variedade do ciclo de vida dos produtos, sendo alguns dos fatores que proporcionam um ambiente de competitividade elevado. Esses fatores trouxeram consigo novas necessidades quanto à utilização das informações contábeis, tornando-se uma ferramenta vital na gestão estratégica de custos das empresas. Em decorrência dessas transformações, fez-se necessária a aplicação de processos que viabilizassem operacionalizar essas exigências (Cruz \& Rocha, 2008).

Nessa conjuntura, Gomes, Moreira e Colauto (2010) afirmam que a competitividade do mercado, associada ao aumento da exigência dos clientes, referenda o entendimento anterior sobre a necessidade de as empresas investirem na melhoria dos processos de formação de preço em função tanto da redução do ciclo de vida dos produtos quanto pela maior oferta no mercado.

Portanto, o custeio-alvo é considerado como uma prática de controle gerencial que observa o posicionamento estratégico da empresa. Rocha e Marques (2015) 
Custeio-Alvo: Um Caso Prático em uma Indústria de Confecções do Polo Têxtil do Agreste

Pernambucano

Monike Silva Melo, Antônio André Cunha Callado

entendem que o custeio-alvo "utiliza um processo de gerenciamento de custos de produtos por meio da determinação e obtenção do custo alvo, assegurando que durante o ciclo de vida gere o retorno desejado garantindo os requisitos dos clientes".

As exigências dos clientes por mais qualidade e diversidade causam redução do ciclo de vida dos produtos, o que torna o planejamento e controle de custos nos estágios de pesquisa e desenvolvimento essenciais para a sobrevivência das empresas (Ferreira \& Machado, 2015).

Nesse cerne, o Custeio-Alvo apresenta-se como uma ferramenta de gestão estratégica de custos, visto que é uma técnica que determina o custo máximo admitido do produto ou serviço que se mostre aceitável na visão do cliente, baseando-se sempre no preço que o mercado está disposto a pagar, subtraindo a margem de lucro desejada, dessa forma sendo capaz de subsidiar os gestores com informações de custos para o desenvolvimento de novos produtos.

Dando corpo a essa discussão, Camacho, Biazebete e Bortinelli (2009) defendem como axioma que as indústrias de confecções no Brasil enfrentam um elevado grau de competitividade, assim como outros setores de atividade. Dessa forma, entende-se como necessário o aprimoramento e a aplicação de ferramentas eficientes e eficazes de gerenciamento de custos dos produtos.

Destaca-se ainda que essas empresas, em sua maioria, tenham uma elevada deficiência em relação às suas informações de custos de produção e a intenção em conseguir acompanhar a velocidade das mudanças tecnológicas sempre com o objetivo de melhorar seus produtos e serviços e atender as necessidades dos seus clientes.

Para Camacho et al., (2009), frequentemente organizações do setor de confecções se deparam com dificuldades decorrentes dos preços que os consumidores estão dispostos a pagar sendo estes inferiores aos custos estimados dos seus produtos. 
Custeio-Alvo: Um Caso Prático em uma Indústria de Confecções do Polo Têxtil do Agreste

Pernambucano

Monike Silva Melo, Antônio André Cunha Callado

Dispor de metodologias de apuração, controle e gerenciamento de custos que se adaptem às características da empresa é um grande desafio, tendo em vista a necessidade destas em encontrar meios para garantir sua continuidade no mercado (Camacho et al., 2009).

Diante desse cenário, o presente estudo direciona-se ao campo empírico, aplicação da metodologia do Custeio-Alvo em uma indústria de confecções de moda íntima, tendo por escopo responder a seguinte questão-problema: como a decomposição das funções do produto pode ajudar a reduzir ou aumentar o custo estimado para o custo permitido?

\section{REFERENCIAL TEÓRICO}

Nesta seção, são apresentadas as perspectivas teóricas que envolvem os debates sobre a Gestão Estratégica de Custos e Custeio-Alvo à luz das contribuições de Shank (1989); Hanssen e Rocha (2004); Camacho et al., (2009); Martins (2003), entre outros.

\subsection{Gestão Estratégica de Custos}

De acordo com Shank (1989), a Gestão Estratégica de Custos é o uso gerencial da informação de custos. Esse conceito tem por base três alicerces: cadeia de valor, que é o conjunto de ações interligadas de atividades criadoras de valor, desde a matéria-prima até o consumidor final; posicionamento estratégico, que é a definição da estratégia que a empresa escolheu seguir e que pode ser a diferenciação do produto ou a liderança em custos; por fim, os direcionadores de custos, que são encontrados de acordo com a escolha estratégica da empresa, variando de acordo com os esforços demandados para a consecução do objetivo: eles podem ser direcionadores estruturais, em que cada escolha da empresa impulsiona o custo do produto e direcionadores executórios, que determinam a posição de custos da empresa em relação à sua capacidade de executar. 
Custeio-Alvo: Um Caso Prático em uma Indústria de Confecções do Polo Têxtil do Agreste

Pernambucano

Monike Silva Melo, Antônio André Cunha Callado

Corroborando esse entendimento, Perez, Oliveira e Costa (2006) afirmam que a empresa pode definir sua estratégia dentro de dois escopos: liderança de custos em relação aos concorrentes ou diferenciação de produtos. Definir o objetivo estratégico representa o direcionador de tudo que é vital para uma organização a fim de manter sua capacidade competitiva e vantagens em relação aos concorrentes.

A contabilidade de custos tradicional fornecia informações de custos evidenciando apenas aspectos relacionados ao impacto financeiro das decisões gerenciais. Essa utilização já não é mais suficiente para atender as demandas dos usuários; há uma necessidade de utilização de informações mais relevantes para uma abordagem que vise ao processo de melhoria contínua de desempenho. (Perez et al., 2006).

O Quadro 1 apresenta uma comparação entre a análise de custos e a gestão estratégica:

\begin{tabular}{|c|c|}
\hline $\begin{array}{l}\text { As informações decorrentes da abordagem } \\
\text { tradicional limitam as seguintes análises: }\end{array}$ & $\begin{array}{l}\text { A gestão estratégica de custos permite a } \\
\text { utilização de ferramentas mais apropriadas } \\
\text { para gestão empresarial: }\end{array}$ \\
\hline 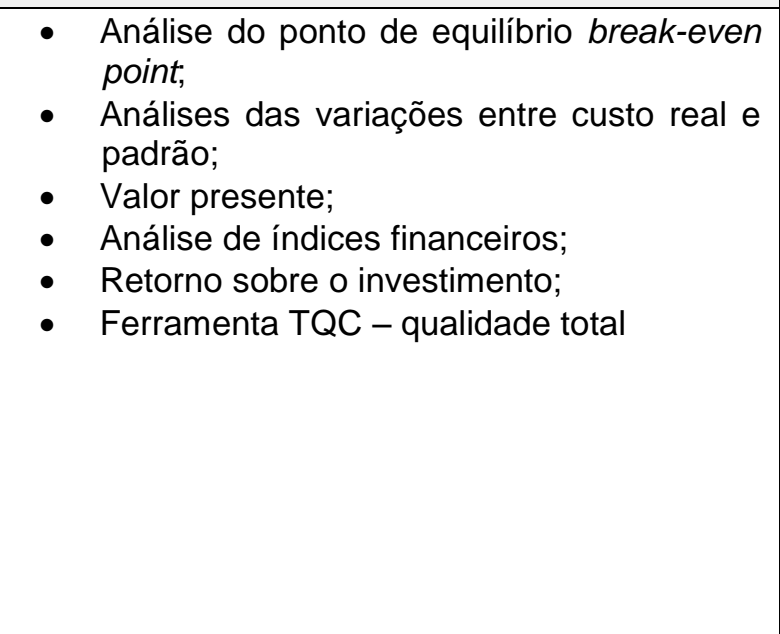 & $\begin{array}{l}\text { - Análise de agrupamentos de atividades; } \\
\text { - Análise dos geradores ou direcionadores } \\
\text { de custos (cost-drivers) } \\
\text { - Análise das atividades que agregam/não } \\
\text { - Anregam valor; } \\
\text { - Análise dos processos operacionais e } \\
\text { - Análise de benchmarking; } \\
\text { - Análise do custo da qualidade; } \\
\text { - Análise da rentabilidade de clientes; } \\
\text { - } \text { operacionais; } \\
\text { - } \text { Análise de fragmentades; } \\
\text { - Custeio de produtos e serviços. }\end{array}$ \\
\hline
\end{tabular}

Quadro 1. Comparativo entre a contabilidade de custos tradicional e a gestão estratégica de custos

Fonte: Adaptado de Perez, Oliveira e Costa (2006). 
Custeio-Alvo: Um Caso Prático em uma Indústria de Confecções do Polo Têxtil do Agreste

Pernambucano

Monike Silva Melo, Antônio André Cunha Callado

Observadas as diferenças entre a abordagem tradicional e a de gestão de custos, fica clara a percepção de que necessidades diferentes exigem dados diferentes. A ideia de modelo único não se aplica à gestão de custos (Maher, 2001).

A gestão estratégica de custos requer uma mudança de comportamento. $\mathrm{O}$ gerenciamento de custos estratégicos representa uma forma diferente de pensar/agir sobre a contabilidade gerencial, o que representa um tipo de mudança de paradigma (Shank, 1989).

\subsection{Custeio-Alvo}

Ao iniciar a discussão acerca dessa temática, faz-se necessário frisar que a definição e o conceito de Custeio-Alvo não são unânimes na literatura. Notadamente, existe uma corrente de pensamento que considera o Custeio-Alvo como sinônimo de custo máximo admissível. Outra corrente pondera o Custeio-Alvo como a diferença entre o custo máximo admissível e o custo estimado (Hansen, \& Rocha, 2004). Para compreender essas diferentes acepções teóricas, apresentam-se as contribuições abaixo elencadas:

Segundo Rocha, Wienhage e Scarpin (2010), o Custeio-Alvo é um método utilizado para o gerenciamento de custos com vistas a atender as necessidades e expectativas do mercado consumidor. Possui uma característica de proatividade quanto à sua abordagem que busca garantir o resultado desejado para um projeto mediante a integração de todas as áreas da empresa.

De acordo com Camacho (2004), Custeio-Alvo "é um processo de gerenciamento de custos por meio do qual se busca o alcance do custo-alvo". Camacho e Rocha (2008) afirmam que o Custeio-Alvo tem por objetivo principal o alcance do lucro-alvo e que esse lucro é dependente das receitas e dos custos. Dessa forma, este sistema de custeio "é fortemente recomendado em situações em que exista pouca ou nenhuma possibilidade de gestão de preços (receitas); resta, como opção, concentrar esforços na gestão dos custos". 
Custeio-Alvo: Um Caso Prático em uma Indústria de Confecções do Polo Têxtil do Agreste Pernambucano Monike Silva Melo, Antônio André Cunha Callado

Para Martins (2003), Custeio-Alvo representa "o custo máximo admissível de um produto para que, dado o preço de venda que o mercado oferece, consiga-se o mínimo de rentabilidade que se quer".

Custeio Alvo pode ser definido como sendo um modelo de gerenciamento de lucros e custos, desenvolvido principalmente para novos produtos (ou produtos que terão seu projeto alterado) visando trazê-los para uma situação de mercado, ou seja, o produto passa a ter um preço de mercado competitivo, proporcionando um retorno do investimento durante todo o seu ciclo de vida a um custo aceitável (custo alvo), determinado pelo seu preço de venda (Scarpin, 2000).

Freitas (2004) traz uma definição mais completa sobre o que seria Custeio-Alvo que englobe todas as suas características e objetivos.

Sistema de gestão estratégica de custos e planejamento de lucros centrado principalmente nas fases de pesquisa, desenvolvimento e engenharia do produto que, guiado pelo preço de mercado, tem por finalidade obter o custo máximo aceitável de um produto, de maneira a alcançar uma rentabilidade razoável, satisfazendo clientes, considerando todo o ciclo de vida do produto e envolvendo toda a estrutura organizacional e cadeia de valor da empresa (Freitas, 2004).

Cruz e Rocha (2008), Hansen e Rocha (2004) afirmam que o Custeio-Alvo pode ser dividido em princípios e requisitos. Os princípios são as bases fundamentais de sua existência e de seu delineamento e são apresentados em quatro grupos, a saber: 
Custeio-Alvo: Um Caso Prático em uma Indústria de Confecções do Polo Têxtil do Agreste

Pernambucano

Monike Silva Melo, Antônio André Cunha Callado

I. O lucro é a garantia de sobrevivência da empresa; a continuidade de qualquer empreendimento ou organização só será alcançada se a estratégia da mesma for determinada em termos de lucro;

II. Custo conduzido pelo preço significa que não são os custos que determinarão o preço de venda, conforme cost plus pricing ou preço com base no custo, mas que a partir do preço de venda é que são estabelecidos os custos a serem incorridos;

III. Satisfação dos clientes significa que a voz do consumidor move todo o processo; e

IV. O custo é definido essencialmente no projeto onde o custeio alvo assume esse princípio considerando que reduções significativas de custos somente são obtidas na fase de projeto do produto.

Sobre os requisitos, Cruz e Rocha (2008) ainda ressaltam que esses princípios são necessários para atingir os objetivos do Custeio-Alvo e elenca apenas três, que são: Envolvimento interfuncional; Orientação para o ciclo de vida do produto; Envolvimento da cadeia de valor.

Para Hansen e Rocha (2004), os requisitos estão divididos em seis: I. o preço deve ser fortemente influenciado pela competição, em que o limite máximo dos custos é determinado por influência direta do mercado; II. O ciclo de vida dos produtos deve ser curto; III. Deve haver envolvimento das pessoas da empresa com o processo do Custeio-Alvo; IV. O Custeio-Alvo deve contemplar todo ciclo de vida do produto; V. O Custeio-Alvo comtemplará o custo total de uso e propriedade para o consumidor; VI. Ter um enfoque externo à empresa, considerando cada empresa no contexto da cadeia global de atividades geradoras de valor.

Custeio Alvo é um processo de planejamento de resultados, com base no gerenciamento de custos e preços, que se fundamenta em preços de venda estabelecidos pelo mercado e nas margens objetivadas pela empresa (Hansen \& Rocha, 2004). 
Custeio-Alvo: Um Caso Prático em uma Indústria de Confecções do Polo Têxtil do Agreste

Entende-se com o exposto que os custos são definidos na fase de projeto de novos produtos (ou de produtos reprojetados), com vistas a atender a demanda dos clientes por meio da otimização do custo de propriedade do consumidor, com envolvimento da empresa e que comtemple todo o ciclo de vida do produto que envolva um segmento relevante de sua cadeia.

Martins (2003) afirma que custo-alvo é "o custo máximo admissível de um produto ou serviço para que, dado o preço de venda que o mercado oferece, consigase o mínimo de rentabilidade que se quer". Em mercados cada vez mais competitivos onde o ciclo de vida dos produtos está cada vez mais reduzido, há uma necessidade para as empresas de reduzirem o tempo de comercialização de novos produtos e, simultaneamente, garantir seu sucesso no mercado. O tempo de comercialização de novos os produtos tornou-se também um fator decisivo de vantagem competitiva (Afonso, Nunes, Paisana \& Braga, 2008).

Maher (2001) define o custo-alvo dizendo que ele "é uma abordagem sistemática para estabelecimento do custo desejado de um produto, com base em fatores ditados pelo mercado". Para Camacho e Rocha (2008), "custo-alvo é a diferença, ou o gap entre o custo estimado e o máximo permitido".

São encontradas na literatura duas formas básicas de uso do Custeio-Alvo: uma que considera o custo-alvo a diferença entre o custo estimado e o máximo permitido, e a outra corrente que considera o custo-alvo a diferença entre o preço de venda-alvo e a margem de lucro almejada. O Quadro 2 apresenta a forma de cálculo das duas. 
Custeio-Alvo: Um Caso Prático em uma Indústria de Confecções do Polo Têxtil do Agreste

\begin{tabular}{|l|c|}
\hline \multicolumn{1}{|c|}{ Corrente 1 } \\
\hline & Valor R\$ \\
\hline Preço de venda alvo & 100,00 \\
\hline Margem de lucro alvo 30\% & 30,00 \\
\hline Custo alvo & 70,00 \\
\hline \multicolumn{2}{|c|}{ Corrente 2 } \\
\hline Preço de venda alvo & 100,00 \\
\hline Margem de lucro alvo 30\% & 30,00 \\
\hline Custo máximo admissível & 70,00 \\
\hline Custo estimado & 75,00 \\
\hline Custo Alvo (Gap) & $(5,00)$ \\
\hline
\end{tabular}

\section{Quadro 2. Cálculo do custo alvo}

Fonte: Adaptado de Camacho et al. (2009)

Segundo Crepaldi (2004), o Custeio-Alvo, definido como custo-meta, é uma forma de gerenciamento estratégico dos custos com o objetivo de reduzi-los e alcançar a margem de lucro-alvo definida pela empresa. O diferencial desse método é a projeção de produtos que possam satisfazer os clientes com características e funcionalidades específicas para atingir uma posição significativa no mercado. Nesse caso, o preço de mercado é que determina os custos, e esses são geridos por todas as partes da empresa envolvidas no processo, por meio de equipes multidepartamentais de toda a cadeia operacional, havendo, portanto, uma inter-relação entre todos os agentes envolvidos nesse processo (Perez, Oliveira, \& Costa, 2006).

O Custeio-Alvo é considerado uma ferramenta de apoio para a implementação de novos produtos no mercado. Por meio dele, é projetado o lucro alvo; em seguida, é extraído o preço de venda estimado para assim ser determinado o custo-alvo.

Para a execução do planejamento, é preciso a interligação de todos os departamentos envolvidos no projeto e a fabricação do produto para atender o custometa, em que marketing, contabilidade e pessoal de fabricação trabalham juntos para trazer produtos a preços competitivos; poderá ser necessário melhorar o processo geral de desenvolvimento de produtos (Gagne \& Discenza, 1995). 
Custeio-Alvo: Um Caso Prático em uma Indústria de Confecções do Polo Têxtil do Agreste

Pernambucano

Monike Silva Melo, Antônio André Cunha Callado

\subsection{Objetivos do Custeio-Alvo}

Farias, Freitas e Marion (2009) afirmam que o Custeio-Alvo se direciona mais fortemente para a etapa de desenvolvimento do projeto do produto na fase de concepção, momento no qual é possível executar as maiores mudanças na estrutura de custos do mesmo.

O principal objetivo é determinar se é possível produzir mais barato, mais rapidamente, com melhor margem e com maior qualidade frente a produtos similares disponibilizados pela concorrência (Farias, Freitas, \& Marion, 2009).

Para Hansen e Rocha (2004), os objetivos do Custeio-Alvo são divididos em cinco e resumidos a seguir:

a. Alcançar o lucro alvo, tornando a obtenção do custo alvo uma atividade de administração do lucro por toda a empresa.

b. Mudança na visão da formação do preço de venda, onde o custo não é o fator que determina o preço e sim o preço é que determina o custo.

c. Promover uma completa integração entre todos os setores da empresa, objetivando 0 envolvimento de todos em perfeita sintonia para o funcionamento correto do Custeio Alvo a fim de que os esforços para gestão de custos consigam ser plenamente atingidos.

d. Fazer análise de custos considerando todo ciclo de vida produto, visando otimizar o custo de propriedade do consumidor (Total Cost of Ownership TCO).

e. Otimização do custo total do produto sem fazê-lo perder, contudo, seu padrão de qualidade.

São requisitos do Custeio-Alvo para a obtenção de certos objetivos ou para atingir determinado fim: que o preço seja fortemente influenciado pela competição, assim como o ciclo de vida dos produtos deve ser curto; as pessoas da empresa devem estar envolvidas no projeto e comprometidas com o processo para atingir o custo-alvo; 
Custeio-Alvo: Um Caso Prático em uma Indústria de Confecções do Polo Têxtil do Agreste

Pernambucano

Monike Silva Melo, Antônio André Cunha Callado

deve contemplar o custo total de uso e propriedade para o consumidor e deve comtemplar um segmento relevante da cadeia na qual a empresa está envolvida (Hansen \& Rocha, 2004).

Segundo Monden (1999), o Custeio-Alvo possui duas premissas básicas. A primeira refere-se à redução dos custos de novos produtos com vistas a alcançar o lucro pretendido sem esquecer a necessidade de garantir os níveis de qualidade, tempo de entrega e preço aceitável pelo mercado. A segunda refere-se a um meio de motivar os funcionários para alcançar o lucro-alvo durante o processo de planejamento do produto ou serviço com vistas a atingir o custo-alvo. Como observado nas definições anteriores, observa-se que esses são de fatos pressupostos do Custeio-Alvo, mas não são as únicas.

\subsection{Características do Custeio-Alvo}

Na opinião de Cooper e Slagmulder (1997) apud Faria, Freitas e Marion (2009), o Custeio-Alvo é um método que possui três grandes características: a primeira refere-se ao fato de os custos serem permitidos ou determinados pelo mercado; a segunda característica fala da integração que deve existir em todas as áreas envolvidas com a produção, objetivando alcançar os custos permitidos pelo mercado, e a terceira é que os custos e os lucros são planejados para o longo prazo.

Ewert e Ernst (1999) afirmam que o Custeio-Alvo é uma ferramenta de contabilidade gerencial estratégica e possui três características distintas: "sua orientação para o mercado, seu uso como instrumento de coordenação e sua interação com outros fatores que afetam a estrutura de custos de longo prazo".

Afonso et. al. (2008) corroboram a definição de características atribuídas ao custo-meta quando afirmam que o custo-meta é um processo de três etapas. Primeiramente, o preço-meta é identificado mediante análise de mercado. Em seguida, uma margem-meta é determinada. Por último, o custo-meta é calculado subtraindo-se sua margem-meta de seu preço-meta. Os autores afirmam que, como suporte para 
Custeio-Alvo: Um Caso Prático em uma Indústria de Confecções do Polo Têxtil do Agreste

Pernambucano

Monike Silva Melo, Antônio André Cunha Callado

atingir o custo-meta, são usadas informações de Engenharia de Valor (VE) e Análise de Custos Funcionais (FCA).

Para Hansen e Rocha (2004), o Custeio-Alvo possui três características: A primeira é que a determinação dos custos que antes eram definidos dentro da empresa passou para custos permitidos pelo mercado.

O método utilizado para se obter o custo permissível - o mais alto valor admissível para o custo do produto - passou a ser o preço de venda estabelecido com base no mercado para um produto particular, menos a rentabilidade mínima desejada (Hansen \& Rocha, 2004).

Por essa razão, para que a colocação do produto no mercado seja bemsucedida, é preciso integração e esforços de todas as áreas da empresa para atingir o nível dos custos permissíveis.

O objetivo perseguido é determinar se ainda é possível produzir mais barato, mais rápido, com melhor margem e com maior qualidade do que a concorrência. Se não for possível atingir o custo máximo permitido pelo mercado, o produto não deve ser produzido (Hansen \& Rocha, 2004).

Com a segunda característica de Hansen e Rocha (2004), aprende-se que, para o alcance do custo-alvo, é necessário o envolvimento de toda a equipe que faz parte do projeto do produto. "Os esforços necessários para se atingir o custo máximo permitido pelo mercado devem incluir a articulação de toda a equipe envolvida no desenvolvimento do produto" (Hansen \& Rocha, 2004).

A terceira característica é que Hansen e Rocha (2004) trabalham com o gerenciamento de custos ainda na fase de projeto; é um sistema de planejamento de lucros e gerenciamento de custos a longo prazo. Nessa etapa, é possível modificar o projeto respeitando sempre as necessidades do cliente e as funções consideradas importantes. 
Custeio-Alvo: Um Caso Prático em uma Indústria de Confecções do Polo Têxtil do Agreste Pernambucano Monike Silva Melo, Antônio André Cunha Callado

É na fase de projeto do produto que estão as circunstâncias favoráveis para modificar o custo de um novo produto, o que não ocorre após o produto entrar em sua fase de produção (Hansen \& Rocha, 2004).

Com base na fundamentação teórica apresentada por meio das definições de conceitos, características e objetivos, serão apresentadas as etapas de implantação deste método de gerenciamento de custos.

De acordo com o entendimento de Foster, Horngren e Datar (2000), a implantação do Hansen e Rocha (2004) deve seguir as seguintes etapas obrigatoriamente: Desenvolvimento de um produto que contemple o objetivo de atender as necessidades potenciais dos clientes; Identificação do preço-meta, com base no valor que os clientes estão dispostos a pagar pelo produto e sempre observando os preços praticados pelos concorrentes; identificação do custo-meta unitário encontrado na diferença entre o preço-meta por unidade e o lucro operacional meta unitário; por fim, a utilização da Engenharia de Valor (ou análise de valor) para alcance do custometa.

Caseirão (2002) apud Freitas (2004) descreve, de maneira similar, as fases de implantação, mas de uma forma mais robusta e detalhada das etapas. 
Custeio-Alvo: Um Caso Prático em uma Indústria de Confecções do Polo Têxtil do Agreste Pernambucano

Monike Silva Melo, Antônio André Cunha Callado

$1^{\circ-}$ - A empresa define o produto que deseja fabricar e comercializar, analisa o mercado e a concorrência e fixa o preço de venda alvo (target selling price), ou seja, o valor que o mercado está disposto a pagar pelo produto;

$2^{\circ}$ - É definida a margem de lucro (target profit mangin), tendo em consideração que a mesma deve permitir a recuperação dos custos de investimento e desenvolvimento do projeto;

3ํ-- Determina-se o custo máximo de produção (Target Costing) a atingir - pela diferença entre o preço de venda alvo e a margem de lucro alvo - o qual deverá ser objeto de ajustamentos à medida que se forem introduzindo novos componentes do custo, e se forem colmatando imperfeições de desenho e de produção;

4ํ- É necessário assegurar que as equipes de desenho, engenharia e produção vão conseguir desenhar, planificar e produzir o produto final de forma a que, sem sacrificar a qualidade, pressuposto fundamental a respeitar, o produto possa ser produzido pelos custos previamente definidos.

De acordo com o exposto, fica clara a sequência necessária para aplicação do custeio-alvo no gerenciamento de custos das organizações.

\subsection{Engenharia de Valor}

Colauto e Beuren (2004) afirmam que a engenharia de valor (EV) deve ser entendida como a essência do custo-meta, tendo em vista que "envolve os esforços organizados no sentido de implementar análise funcional do produto para atingir, com maior grau de confiabilidade, todas as funções requeridas do ciclo de vida, ao menor custo possível".

Segundo Gomes et al., (2010), a engenharia de valor também requer a sinergia das diversas áreas da empresa. "A análise é realizada pelos engenheiros dos projetos e demais especialistas, além das áreas administrativas, como compras, contabilidade de custos e vendas, e ainda pela produção". 
Custeio-Alvo: Um Caso Prático em uma Indústria de Confecções do Polo Têxtil do Agreste

Freitas (2004) afirma não ter dúvidas sobre a importância da engenharia de valor relacionada ao papel crucial que desempenha no atingimento do custo alvo e, como consequência, no processo de aplicação do custeio alvo.

A engenharia de valor é o processo pelo qual são analisados os materiais e os processos de produção por meio do desenvolvimento e da redução dos custos pela geração de ideias para a redução de ambos.

Atkinson et al. (2000) atribuem a engenharia de valor à responsabilidade no "Processo de examinar cada componente de um produto para determinar se seu custo pode ser reduzido enquanto mantém a funcionalidade e o desempenho".

\subsection{Custeio Pleno}

De acordo com Vartanian e Nascimento (1999), "O método de custeio pleno é aquele em que todos os custos e despesas de uma entidade são levados aos objetos de custeio, normalmente unidades de produtos e/ou ordens de serviço".

Souza e Salvalaio (2010) consideram o custeio pleno mais abrangente e afirmam que, no método do custeio pleno, são considerados todos os gastos gerados sem separação entre custos ou despesas; logo, considera-se a totalidade dos gastos.

A principal vantagem do método de custeio pleno é o fato de serem levados em conta todos os gastos ocorridos em uma organização, sem exceções. Obtém-se, dessa forma, uma informação de custos unitária completa e conservadora. E a principal desvantagem está relacionada à arbitrariedade do método quanto ao rateio dos gastos fixos (Vartanian \& Nascimento, 1999).

Segundo Martins (2003), o custeio pleno é o método pelo qual todos os custos e despesas de uma entidade, sejam eles de natureza fixa ou variável, diretos ou indiretos, são atribuídos ao produto. Consiste no rateio não só dos custos de produção como também de todas as despesas da empresa, inclusive financeiras, a todos os produtos (Martins, 2003). 
Custeio-Alvo: Um Caso Prático em uma Indústria de Confecções do Polo Têxtil do Agreste

Pernambucano

Monike Silva Melo, Antônio André Cunha Callado

\section{METODOLOGIA}

Esta seção destina-se a apresentar as escolhas metodológicas e de operacionalização da pesquisa. O estudo definiu-se, com base em seus objetivos, como descritivo, documental e estudo de caso. Por suas características, trata-se de uma pesquisa descritiva, haja vista que se propõe apresentar, analisar, registrar e interpretar os fatores determinantes de comparação entre teoria e prática sobre Hansen e Rocha (2004). Conforme Gil (2010), o objetivo principal das pesquisas descritivas consiste em apresentar as características de determinada população ou fenômeno.

Quanto aos procedimentos técnicos, que é a forma pela qual se obtêm os dados para análise, se caracteriza como uma pesquisa documental e estudo de caso. Gil (2002) defende que "a pesquisa documental vale-se de materiais que não receberam ainda um tratamento analítico, ou que ainda podem ser reelaborados de acordo com os objetos da pesquisa". De acordo com Boaventura (2004), o estudo de caso possui uma metodologia de pesquisa classificada como aplicada, na qual se busca a aplicação prática de conhecimentos para a solução de problemas sociais.

Com relação à abordagem do problema, Prodanov e Freitas (2013) afirmam que, em pesquisa qualitativa, "há uma relação dinâmica entre o mundo real e o sujeito, isto é, um vínculo indissociável entre o mundo objetivo e a subjetividade do sujeito que não pode ser traduzido em números".

O estudo foi realizado por meio da análise de um caso, desenvolvido no ano de 2018, em uma empresa familiar com vinte anos no mercado, situada no Polo Têxtil do Agreste Pernambucano, que atua no setor de confecções de moda íntima feminina e masculina. A empresa utiliza o método de custeio pleno para identificar o custo do novo produto que fará parte da nova coleção da empresa, considerando-se todos os custos de produção e despesas. Com o cálculo do custo do produto, foi aplicada a metodologia do custeio-alvo, para identificar se o custo de produção iria garantir a margem de lucro que a empresa pretendia obter com o lançamento do modelo, dado o preço que o mercado estava disposto a pagar. 
Foi atribuído grau de importância a cada componente do produto; a escala foi desenvolvida pela equipe de design da empresa baseada em pesquisa de opinião feita na loja da fábrica durante os atendimentos aos clientes. A escala de importância variava de 1 a 3 , em que 1 é considerado pouco, 2 médio e 3 muito. Após o levantamento dos dados, foi feita a da média de respostas de acordo com cada item. A equipe de design, no estudo de quais componentes poderiam ser retirados ou trocados com o intuito de atingir o custo-alvo, levou em consideração o rigor exigido pelos pressupostos do Custeio-Alvo. Como afirmado por Monden (1999), a redução dos custos de novos produtos com vistas a alcançar o lucro pretendido não poderá desconsiderar a necessidade de garantir os níveis de qualidade, tempo de entrega e preço aceitável pelo mercado.

As variáveis são os elementos observáveis. Possuem ligação entre si para gerar um fenômeno e estão nas bases de uma pesquisa científica. "Variáveis são, portanto, características observáveis do fenômeno a ser estudado e existem em todos os tipos de pesquisa" (Prodanov \& Freitas, 2013).

As características analisadas no estudo foram: o projeto do produto, o sistema de custeio utilizado pela empresa, o preço de venda-alvo, o lucro-alvo, o custo-alvo, a logística de produção da empresa, a engenharia de valor na aplicação do custeio- alvo e as pessoas envolvidas no processo. Elas podem assumir diferentes características, enquanto nas pesquisas quantitativas são medidas, nas qualitativas, elas são descritas ou explicadas (Gil, 2002).

No processo de operacionalização do estudo, utilizou-se para a coleta de dados entrevista estruturada e observação direta. Gil (2002) afirma que a entrevista, entre todas as técnicas de interrogação, é a que possui uma característica de maior flexibilidade e que pode assumir várias estruturas, entre elas a totalmente estruturada, que é quando se desenvolve a partir de relação fixa de perguntas e o entrevistador segue um roteiro previamente estabelecido. Nesse caso, não é permitida a realização de mudanças nas perguntas a determinada situação, inverter a ordem ou elaborar outras perguntas. As entrevistas foram realizadas com o administrador e pelos 
Custeio-Alvo: Um Caso Prático em uma Indústria de Confecções do Polo Têxtil do Agreste

Pernambucano

Monike Silva Melo, Antônio André Cunha Callado

profissionais responsáveis pelo departamento produtivo e pelo departamento de design do produto.

Kauark, Manhães e Medeiros (2010) defendem que na observação "são aplicados atentamente os sentidos a um objeto, a fim de que se possa, a partir dele, adquirir um conhecimento claro e preciso".

Em sua estruturação, foi aplicada a observação sistemática, também designada como observação planejada ou controlada; é concebida e realizada dentro de condições controladas para o atendimento dos objetivos e propósitos de antemão definidos (Kauark et al., 2010). As observações diretas foram realizadas sobre o processo produtivo e sobre o setor administrativo da empresa analisada. Também foram coletados documentos fornecidos pela empresa, como planilhas e relatórios da área contábil.

\section{ANÁLISE DOS RESULTADOS}

Nesta seção, serão apresentados os resultados encontrados na pesquisa, à luz da metodologia do custeio-alvo na literatura.

A empresa estudada está situada no polo têxtil do Agreste Pernambucano há vinte anos. Trata-se de uma empresa familiar. Produz roupas íntimas femininas e masculinas, mas a maior parte de seu público é composto por mulheres. O produto do estudo foi um sutiã de renda com design diferenciado, que é um acessório do guardaroupa feminino.

A região em que a empresa está inserida é de alta competitividade e o mercado impõe o preço que está disposto a pagar pelo produto. A empresa possui um posicionamento estratégico de liderança em custos e afirma que também tem preocupação com a qualidade dos produtos.

O preço de venda do produto foi determinado em $\mathrm{R} \$ 22,00$ (vinte e dois reais), que foi o valor encontrado mediante pesquisa no mercado local. Após a definição do 
Custeio-Alvo: Um Caso Prático em uma Indústria de Confecções do Polo Têxtil do Agreste

Pernambucano

Monike Silva Melo, Antônio André Cunha Callado

preço de venda do produto com base no mercado, a margem de lucro alvo que a empresa objetiva é de $20 \%$ sobre o valor de venda do produto, ou seja, $R \$ 4,40$.

A Tabela 1 apresenta o cálculo do custo-alvo máximo admitido.

Tabela 1

Cálculo do custo-alvo

\begin{tabular}{lc}
\hline \multicolumn{1}{c}{ Descrição } & Valor $\mathbf{R} \mathbf{\$}$ \\
\hline Preço de venda bruto & 22,00 \\
- Margem de lucro alvo 20\% & 4,40 \\
= Custo alvo & 17,60 \\
\hline
\end{tabular}

Nota. Fonte: Adaptado de Camacho et al. (2009)

De acordo com a Tabela 1, para alcançar a margem de lucro objetivada de $R \$$ 4,40 , o custo máximo admissível é de $R \$ 17,60$.

Como dito anteriormente, a empresa utilizou o custeio pleno para definir o custo estimado do produto. Conforme será apresentado na Tabela 2, foram atribuídos ao produto todos os custos e despesas durante o processo produtivo, como: mão de obra, custos diretos, custos indiretos, matéria-prima e despesas gerais. A empresa disponibilizou essas informações por meio de relatórios e das entrevistas realizadas. Dessa forma, foi possível fazer o levantamento dos custos totais do produto. Foi solicitada área de design que atribuísse um grau de importância a cada parte do sutiã para que, caso se fizesse necessária a subtração de algum item, fosse realizada nos itens considerados menos importantes na concepção dos usuários.

O custo-alvo é um reflexo da posição estratégica da empresa porque deve ser baseada em seus objetivos estratégicos de longo prazo. Cooper e Slagmulder (2000), apud Colauto e Beuren (2005), afirmam que o estabelecimento de metas para redução do custo-alvo deve ser feito de forma alcançável, porque o estabelecimento de metas muito altas poderá exaurir os funcionários, mas eles afirmam também que estabelecer metas demasiadamente baixas pode acarretar a perda da competitividade. 
Custeio-Alvo: Um Caso Prático em uma Indústria de Confecções do Polo Têxtil do Agreste

Pernambucano

Monike Silva Melo, Antônio André Cunha Callado

A Tabela 2 apresenta as informações detalhadas do cálculo estimado dos custos do produto de acordo com as informações disponibilizadas pela empresa.

Tabela 2

Custos estimados dos materiais para o produto

\begin{tabular}{|c|c|c|c|c|c|}
\hline ITEM & $\begin{array}{l}\text { UNIDADE } \\
\text { CONSUMO }\end{array}$ & QUANTIDADE & $\begin{array}{c}\text { GRAU DE } \\
\text { IMPORTÂNCIA } \\
\text { DE CADA ITEM }\end{array}$ & $\begin{array}{c}\text { VALOR TOTAL } \\
\text { DA UNIDADE } \\
\text { R\$ }\end{array}$ & $\begin{array}{c}\text { VALOR } \\
\text { UNITÁRIO } \\
\text { R\$ }\end{array}$ \\
\hline Malha & $\mathrm{m}$ & 0,4 & Muito & 11,00 & 4,40 \\
\hline Renda & $\mathrm{m}$ & 0,2 & Muito & 15,00 & 3,00 \\
\hline Forro & $\mathrm{m}$ & 0,4 & Muito & 5,00 & 0,50 \\
\hline Elástico & $\mathrm{m}$ & 1 & Muito & 0,80 & 0,80 \\
\hline Alças & Par & 1 & Muito & 2,00 & 1,40 \\
\hline Fecho & Par & 1 & Muito & 1,00 & 1,00 \\
\hline Etiqueta & Unidade & 1 & Médio & 0,10 & 0,10 \\
\hline $\begin{array}{l}\text { Placa da } \\
\text { etiqueta de } \\
\text { metal }\end{array}$ & Unidade & 1 & Pouco & 1,10 & 1,10 \\
\hline Laço & Unidade & 1 & Pouco & 0,80 & 0,80 \\
\hline Bojo & Par & 1 & Muito & 1,80 & 1,40 \\
\hline Arco & Par & 1 & Muito & 0,50 & 0,50 \\
\hline \multicolumn{5}{|c|}{ Custo total dos materiais $\mathrm{R} \$$} & 15,00 \\
\hline
\end{tabular}

Nota. Fonte: Adaptada de Camacho et al. (2009).

Após a definição dos custos estimados do produto, foi feita a apresentação dos custos da empresa como um todo, referente à mão de obra direta, todos os custos indiretos e todas as despesas administrativas referentes ao mês de junho de 2018. A empresa apresentou, em seus informes, que tem uma média de venda mensal de 6.000 peças de todos os seus produtos. Essas informações são referentes a todos os gastos de produção de todos os produtos não só do sutiã. A empresa paga comissões de venda aos vendedores de $1 \%$ sobre o preço de venda. É optante do Simples nacional, e sua alíquota atual é de $5,97 \%$.

A Tabela 3 apresenta as informações sobre todos os seus gastos. Como o método utilizado pela empresa é o custeio pleno, todos os gastos foram divididos pelo total produzido no mês, que foi de 6.000 unidades. 
Custeio-Alvo: Um Caso Prático em uma Indústria de Confecções do Polo Têxtil do Agreste

Pernambucano

Monike Silva Melo, Antônio André Cunha Callado

Tabela 3

Todos os gastos da empresa

\begin{tabular}{lcc}
\hline \multicolumn{1}{c}{ ELEMENTO DE CUSTO } & CUSTO TOTAL R\$ & CUSTO UNITÁRIO R\$ \\
\hline Total dos custos diretos e indiretos & $12.176,00$ & 2,04 \\
Total das despesas & $12.917,28$ & 2,16 \\
Custo Total Estimado & $\mathbf{2 5 . 0 9 3 , 2 8}$ & $\mathbf{4 , 2 0}$ \\
Impostos 5,97\% & 22,00 & 1,31 \\
Comissões de vendas 1\% & 22,00 & 0,22 \\
Total dos Gastos R\$ & & $\mathbf{5 , 7 3}$ \\
\hline
\end{tabular}

Nota. Fonte: Adaptada de Camacho et al. (2009).

Com essas informações disponibilizadas, é possível chegar ao custo estimado do produto que é a soma dos custos de materiais do produto que foram de $R \$ 15,00$ (Tabela 2), mais os gastos individuais de $\mathrm{R} \$ 5,73$ (Tabela 3 ) nesse valor, já inclusos comissões de vendas e impostos. Portanto, o custo estimado do sutiã foi de $R \$ 20,73$. Como pode ser observado, os custos estimados do produto são quase o mesmo do preço de venda dele. A empresa precisa rever os custos e os processos de fabricação para tentar alcançar o custo-alvo permitido.

A Tabela 4 apresenta a diferença e o percentual de redução necessário para o alcance do custo-alvo.

Tabela 4

Comparação do custo estimado com o custo alvo.

\begin{tabular}{lc}
\multicolumn{1}{c}{ Descrição } & Valor R\$ \\
\hline Custo alvo - Tabela 1 & 17,60 \\
Custo estimado - Tabela 2 e 3 & 20,73 \\
GAP & 3,13 \\
GAP \% & 17,78 \\
\hline
\end{tabular}

Nota. Fonte: Adaptada de Camacho et al. (2009).

Como pode ser observado, de acordo com a Tabela 4, do resultado da comparação entre o custo estimado e o custo-alvo é encontrado um GAP de $R \$ 3,13$, que representa $17,78 \%$ do custo-alvo do produto. O GAP refere-se ao custo que deverá 
Custeio-Alvo: Um Caso Prático em uma Indústria de Confecções do Polo Têxtil do Agreste

Pernambucano

Monike Silva Melo, Antônio André Cunha Callado

ser eliminado do produto para que a margem de lucro-alvo definida pela empresa seja atingida.

Para eliminar $G A P$ de $R \$ 3,13$ referente aos custos estimados para que 0 produto pudesse seguir para linha de produção, foi preciso o envolvimento da equipe administrativa para realizar a negociação junto aos fornecedores para a possível redução dos custos da matéria-prima, pesquisa junto às consumidoras sobre o grau de importância dos itens do produto e também da equipe de design indicar quais as possíveis trocas e retiradas dos itens que compõem o produto não trariam prejuízo à qualidade do mesmo. Além da redução por meio da retirada ou troca de itens e negociação de preços com fornecedores, foi preciso o envolvimento do setor de produção da organização na melhoria do processo de fabricação do produto. Por meio dessa melhoria, com o envolvimento de todos os componentes da cadeia de produção, seria possível o alcance da redução do GAP encontrado. Colauto e Beuren (2005) afirmam que

... a técnica de engenharia de valor envolve uma abordagem multidisciplinar do projeto do produto para maximizar o valor para o cliente, por meio da manutenção da qualidade e funcionalidade do produto e, ao mesmo tempo, reduzir os custos.

No primeiro momento, foi sugerido que fossem retirados dos produtos os dois itens que obtiveram pouco grau de importância pelas consumidoras e que foram considerados pela equipe de design como itens que, com suas retiradas, não trariam prejuízo à concepção do sutiã.

Com essa possibilidade de retirada, já seriam reduzidos dos custos de materiais $R \$ 1,10$ da placa de metal e mais $R \$ 0,80$ do laço, perfazendo um total de redução de $R \$ 1,90$. A pessoa responsável pela compra da malha afirmou que não seria possível a redução do preço do metro, tendo em vista que esse valor já havia sido negociado com o fornecedor. Foi então sugerido a troca do tipo de malha e da renda por um tipo com custo mais baixo. 
Custeio-Alvo: Um Caso Prático em uma Indústria de Confecções do Polo Têxtil do Agreste Pernambucano

Monike Silva Melo, Antônio André Cunha Callado

O valor da malha e da renda substituta é, respectivamente, $R \$ 10,00$ e $R \$ 13,00$ e a redução do custo seria $R \$ 0,40$ em ambos, totalizando uma redução de $R \$ 0,80$. Outro item que não foi considerado como muito importante foi a etiqueta de nylon que poderia ser substituída por outro tipo, mas como o valor é muito baixo e a empresa compra essa etiqueta em grandes quantidades para todos os seus produtos, foi considerado melhor não mexer nesse item.

Em relação aos demais gastos, a empresa afirmou não ser possível redução tendo em vista que há pouco tempo passou por uma reestruturação e que já havia feito alterações para redução dos gastos. A Tabela 5 apresenta os custos após as sugestões de mudança.

Tabela 5

Novo custo estimado dos materiais do produto

\begin{tabular}{|c|c|c|c|c|c|}
\hline ITEM & $\begin{array}{l}\text { UNIDADE } \\
\text { CONSUMO }\end{array}$ & QUANTIDADE & $\begin{array}{c}\text { GRAU DE } \\
\text { IMPORTÂNCIA } \\
\text { DE CADA ITEM }\end{array}$ & $\begin{array}{c}\text { VALOR TOTAL } \\
\text { DA UNIDADE } \\
\text { R\$ }\end{array}$ & $\begin{array}{c}\text { VALOR } \\
\text { UNITÁRIO } \\
\text { R\$ }\end{array}$ \\
\hline Malha & $\mathrm{m}$ & 0,4 & Muito & 10,00 & 4,00 \\
\hline Renda & $\mathrm{m}$ & 0,2 & Muito & 13,00 & 2,60 \\
\hline Forro & $\mathrm{m}$ & 0,4 & Muito & 5,00 & 0,50 \\
\hline Elástico & $\mathrm{m}$ & 1 & Muito & 0,80 & 0,80 \\
\hline Alças & Par & 1 & Muito & 2,00 & 1,40 \\
\hline Fecho & Par & 1 & Muito & 1,00 & 1,00 \\
\hline Etiqueta nylon & Unidade & 1 & Média & 0,10 & 0,10 \\
\hline Bojo & Par & 1 & Muito & 1,80 & 1,40 \\
\hline Arco & Par & 1 & Muito & 0,50 & 0,50 \\
\hline \multicolumn{3}{|c|}{ Custo total dos materiais $\mathbf{R} \$$} & & & 12,30 \\
\hline
\end{tabular}

Nota. Fonte: Adaptado de Camacho et al. (2009).

Com a apresentação do novo custo estimado dos materiais após as reduções e subtrações que se fizeram necessárias, é realizada a análise do impacto dessa redução nos gastos totais com o produto para, a partir dos novos resultados, ser feita a análise do novo custo máximo admissível. O valor do custo máximo admissível após as alterações alcançadas com aplicação do método de custeio-alvo foi elaborado na Tabela 6. 
Custeio-Alvo: Um Caso Prático em uma Indústria de Confecções do Polo Têxtil do Agreste

Pernambucano

Monike Silva Melo, Antônio André Cunha Callado

Tabela 6

Gastos estimados do produto após a aplicação do custeio-alvo

\begin{tabular}{|c|c|}
\hline $\begin{array}{c}\text { DESCRIÇÃO DOS COMPONENTE DOS } \\
\text { GASTOS }\end{array}$ & VALOR R\$ \\
\hline Custos estimados $(15,00-2,70)$ Tabela 2 & 12,30 \\
\hline Total dos custos diretos e indiretosTabela 3 & 2,04 \\
\hline Total das despesas Tabela 3 & 2,16 \\
\hline Impostos 5,97\% & 1,31 \\
\hline Comissões de vendas $1 \%$ & 0,22 \\
\hline Total dos novos custos estimados & 18,03 \\
\hline
\end{tabular}

Nota. Fonte: Adaptado de Camacho et al. (2009).

As decisões das mudanças adotadas relativas aos itens eliminados e substituídos do produto, se comparadas aos custos estimados para os materiais dos produtos, inicialmente passou de $R \$ 15,00$ (apresentado na Tabela 2) para $R \$ 12,30$ (apresentado na tabela 5), equivalendo a uma redução de $R \$ 2,70$ dos custos dos materiais. Os outros componentes dos gastos não foram objetos de alterações; conforme já explicado, a empresa afirmou não ser possível fazer alterações.

Em seguida, foi realizada uma comparação entre o custo máximo admitido e o novo custo estimado do produto para que seja vislumbrado o impacto no resultado das mudanças feitas no produto. A Tabela 7 apresenta essa comparação.

Tabela 7

Comparação entre o custo máximo admitido e o novo custo estimado

\begin{tabular}{lc}
\hline \multicolumn{1}{c}{ Descrição } & Valor R\$ \\
\hline Novo custo estimado (Tabela 6) & 18,03 \\
Custo máximo admissível (Tabela 1) & 17,60 \\
Custo-alvo & 0,43 \\
Custo-alvo em \% do estimado & 2,44 \\
\hline
\end{tabular}

Nota. Fonte: Adaptado de Camacho et al. (2009).

Como pode ser verificado na Tabela $7 \mathrm{com}$ as alterações realizadas, não foi possível atingir o custo-alvo estimado. Seria preciso uma redução de mais $R \$ 0,43$, mas 
Custeio-Alvo: Um Caso Prático em uma Indústria de Confecções do Polo Têxtil do Agreste

Pernambucano

Monike Silva Melo, Antônio André Cunha Callado

a empresa alegou não ser possível alcaçar esse valor e decidiu reduzir sua margem de lucro e colocar o produto em linha de produção.

A Tabela 8 apresenta a demonstração de resultado com o novo valor do custo estimado para verificar qual o valor de lucro a empresa alcançará.

Tabela 8

\section{Simulação da demonstração de resultado}

\begin{tabular}{lc}
\multicolumn{1}{c}{ Descrição } & Valor $\mathbf{R} \mathbf{\$}$ \\
\hline Preço de venda bruto & 22,00 \\
Novo custo estimado (Tabela 6) & $(18,03)$ \\
Lucro-alvo & 3,97 \\
Lucro-alvo \% & 18,05 \\
\hline
\end{tabular}

Nota. Fonte: Adaptada de Camacho et al. (2009).

Tendo em vista que o lucro-alvo objetivado era de $22 \%$, por sugestão dos administradores da empresa e que o alcançado será de 18,05\%, a empresa considerou que o processo de aplicação do custeio-alvo foi satisfatório e que a redução do lucro objetivado foi considerada aceitável. A organização, mesmo com a redução do seu lucro, optou por seguir com a produção do sutiã e afirmou que o processo de melhoria será contínuo e que poderá, com a curva de apredizagem da produção, sucessivamente reduzir os cutos.

\section{CONCLUSÃO}

O escopo do estudo foi, a partir da decomposição dos itens que compõem o produto, identificar em quais funções seria possível a redução ou aumento dos custos estimados. Para atingir esse objetivo, foi preciso definir as estruturas das funções dos produtos e quais funções são importantes para os usuários de acordo com a percepção da equipe de design. Para atender ao objetivo, a aplicação do custeio-alvo foi realizada de acordo com a metodologia apresentada no referencial teórico. Foi realizado um estudo de caso numa empresa do ramo de confecções situada em uma das regiões 
Custeio-Alvo: Um Caso Prático em uma Indústria de Confecções do Polo Têxtil do Agreste

Pernambucano

Monike Silva Melo, Antônio André Cunha Callado

mais competitivas do estado para esse setor que é o polo têxtil do agreste pernambucano. Mediante as entrevistas realizadas e a visita à empresa, foram feitas as inferências necessárias para atendimento do objetivo do estudo.

Foi constatado que a empresa aplicava, de forma empírica, o método de custeio pleno para apuração dos seus custos. O método de custeio-alvo apresentou adequação com as características da empresa de confecção estudada, tendo em vista que ela possui as propriedades apresentadas pelo método, está inserida num mercado de alta competitividade e o valor de venda de seus produtos é ditado pelo mercado; seu posicionamento estratégico é em liderança em custos e apresenta uma integração entre as pessoas envolvidas para as mudanças que se fazem necessárias tanto no processo produtivo quanto em aspectos administrativos e gerenciais.

$\mathrm{Na}$ aplicação do método de custeio-alvo na empresa, não foi atingido o lucro-alvo objetivado que era de $22 \%$ do preço de venda do produto, como sugerido pelos administradores; o lucro-alvo alcançado foi de $18,05 \%$ e, mesmo com a possibiliade de reduação do lucro, a organização considerou que o processo de aplicação do custeioalvo foi satisfatório e que a redução do lucro objetivado foi considerada aceitável. A organização, mesmo com redução do seu lucro, optou por seguir com a produção do sutiã e afirmou que o processo de melhoria será contínuo e que poderá, com a curva de apredizagem da produção, sucessivamente reduzir os custos.

Por meio do estudo apresentado, pode-se concluir que o método de custeio-alvo é uma ferramenta de gestão estratégica de custos que foi capaz de suprir as necessidades informacionais e de gerenciamento de custos de uma empresa do ramo de confecções na elaboração de novos produtos que teve como fator limitador o preço de venda requerido pelos consumidores. 
Custeio-Alvo: Um Caso Prático em uma Indústria de Confecções do Polo Têxtil do Agreste

Pernambucano

Monike Silva Melo, Antônio André Cunha Callado

\section{REFERÊNCIAS}

Afonso, P., Nunes, M., Paisana, A., \& Braga, A. A. (2008). The influence of time-tomarket and target costing in the new product development sucess. International Journal of production Economics, 115( 2), p. 559-568.

Atkinson, A. A., \& et al. (2000). Contabilidade Gerencial. São Paulo: Atlas.

Boaventura, E. M. (2004). Metodologia da Pesquisa. São Paulo: Atlas.

Camacho, R. R., Biazebete, C. M., \& Bortinelli, M. L. (2009). Análise da aplicação do custeio-alvo e do custeio pleno em indústria de confecções: Um estudo de caso. Revista de Contabilidade e organizações - FEARP/USP, 3(5), p. 44-61.

Camacho, R. R., \& Rocha, W. (2006). Custeio-alvo em serviços hospitalares - um estudo sob o enfoque da gestão estratégica de custos. In: Congresso USP de Controladoria e Contabilidade, São Paulo, SP, Brasil, 6.

Camacho, R. R., \& Rocha, W. (2007). Custeio-alvo: Uma abordagem conceitual e utilitarista. Enfoque Reflexão contábil, Paraná, 26(3), p. 28-38.

Caseirão, Manuel R. et al. Sabe o que é o "target costing"? Recuperado de: <http:

$<$ www.pdo.pt/boletins/lac_outubro97/bo11097h.shtm\#sabe\%200\%20que\%20e/0200>. Acesso em: 04/nov/2002.

Colauto, R. D., \& Beuren, I. M. (2005). O custeio-alvo como suporte às decisões para desenvolver novos produtos: um estudo em indústria moveleira. Revista produção. $5(1)$, p. 1-18.

Cruz, C. V. O. A., \& Rocha, W. (2008). Custeio-alvo: reflexões sobre definições, finalidades e procedimentos. Revista Contemporânea de Contabilidade, Florianópolis, 1(10), p. 31-52.

Ewert, R., \& Ernst, C. (1999). Target costing, coordination and strategic cost management. The European Accounting Review, 8(1), p. 23-49.

Faria, A. C., Freitas, L. H., \& Marion, J. C. (2009). O empreendedor e a aplicação do sistema de custeio-alvo em pequena empresa do segmento de plástico: Uma pesquisa-ação. Revista de Negócios. Blumenau. 14(1), p. 63-81. 
Ferreira, A. C. F., \& Machado, M. J. C. V. (2015). Custeio-Alvo (Target Costing): Revisão de Bibliografia. Revista Gestão \& Tecnologia, Pedro Leopoldo, 15(1), p. 101-126.

Freitas, T. A. P. A. (2004). Muito prazer! Target Costing. In: Congresso USP de Controladoria e Contabilidade. São Paulo, SP, Brasil, 4.

Foster, G. R., Horngren, C. T., \& Datar, S. M. (2000). Contabilidade de Custos. (9a ed.). LTC: São Paulo.

Gagne, M. L., \& Discenza, R. (1995). Target Costing. Journal of Business \& Industrial marketing, 10(1), p. 16-22.

Gomes, A. M. C., Moreira, R. L., \& Colauto, R. D. (2010). Target Costing para formação do preço de venda em produção por encomenda: o caso de uma indústria de plásticos moldados. Revista Mineira Contabilidade. 2(38), p. 22-31.

Hansen, J. E., \& Rocha, W. (2004). Custeio-Alvo: Princípios e Requisitos. In: Congresso Brasileiro de Custos, Porto Seguro, BA, Brasil, 11.

Kauark, F. S., Manhães, F.C., \& Medeiros, C.H. (2010). Metodologia da pesquisa um guia prático. Bahia, Via Litteratum.

Maher, M. (2001). Contabilidade de Custos - Criando Valor para Administração. (1a ed.). São Paulo: Atlas.

Martins, E. (2003). Contabilidade de Custos. (9a ed.). São Paulo: Atlas.

Monden, Y. (1999). Sistemas de Redução de Custos Custo-alvo e Custo Kaisen. Porto Alegre: Bookman.

Rocha, I., Wienhage, P., \& Scarpin, J. E. (2010). Investigação da produção científica relacionada ao Custeio-Meta e Custeio Kaizen no período de 2002 a 2009. Contexto, Porto Alegre, 10(18), p. 75-86.

Rocha, W., \& Marques, K.C.M. (2015). Custeio-alvo e sua contribuição para a implementação das estratégias de negócio de uma subsidiária de origem Asiática. Contabilidade, Gestão de Governança. Brasília. 18(2). P. 160-180.

Scarpin, J. E. (2000). Target costing e sua utilização como mecanismo de formação de preço de venda para novos produtos. (Dissertação de Mestrado). UNOPAR, Londrina, Paraná, Brasil. 
Custeio-Alvo: Um Caso Prático em uma Indústria de Confecções do Polo Têxtil do Agreste Pernambucano

Monike Silva Melo, Antônio André Cunha Callado

Shank, J. K. (1989). Strategic cost management; New wine, or just new bottle? Jornal of Management Accounting Research, 1(Fall), p. 47-65.

Souza, Antônio, M., \& Salvalaio, S. D. (2010). Rede própria ou rede credenciada: análise comparativa de custos em uma operadora brasileira de planos de saúde. Revista Pan-americana de Salud Publica, 28(4), p. 305-310.

Data de Submissão: 23/11/2018

Data de Aceite: 09/05/2019 